\title{
A single bout of resistance exercise improves postprandial lipid metabolism in overweight/obese men with prediabetes
}

\author{
Adam J. Bittel $^{1}$ (D) $\cdot$ Daniel C. Bittel $^{1} \cdot$ Bettina Mittendorfer $^{2} \cdot$ Bruce W. Patterson $^{2} \cdot$ Adewole L. Okunade $^{2}$. \\ Jun Yoshino ${ }^{2} \cdot$ Lane C. Porter $^{2}$ • Nada A. Abumrad ${ }^{2} \cdot$ Dominic N. Reeds $^{2} \cdot$ W. Todd Cade ${ }^{1}$
}

Received: 13 July 2019 / Accepted: 6 November 2019 / Published online: 23 December 2019

(C) Springer-Verlag GmbH Germany, part of Springer Nature 2019

\begin{abstract}
Aims/hypothesis Prediabetes is associated with postprandial hypertriacylglycerolaemia. Resistance exercise acutely lowers postprandial plasma triacylglycerol (TG); however, the changes in lipid metabolism that mediate this reduction are poorly understood. The aim of this study was to identify the constitutive metabolic mechanisms underlying the changes in postprandial lipid metabolism after resistance exercise in obese men with prediabetes.

Methods We evaluated the effect of a single bout of whole-body resistance exercise (seven exercises, three sets, 10-12 repetitions at $80 \%$ of one-repetition maximum) on postprandial lipid metabolism in ten middle-aged ( $50 \pm 9$ years), overweight/obese (BMI: $\left.33 \pm 3 \mathrm{~kg} / \mathrm{m}^{2}\right)$, sedentary men with prediabetes $\left(\mathrm{HbA}_{1 \mathrm{c}}>38\right.$ but $<48 \mathrm{mmol} / \mathrm{mol}[>5.7 \%$ but $\left.<6.5 \%]\right)$, or fasting plasma glucose $>5.6 \mathrm{mmol} / 1$ but $<7.0 \mathrm{mmol} / 1$ or $2 \mathrm{~h}$ OGTT glucose $>7.8 \mathrm{mmol} / 1$ but $<11.1 \mathrm{mmol} / \mathrm{l})$. We used a randomised, crossover design with a triple-tracer mixed meal test (ingested $\left[\left({ }^{13} \mathrm{C}_{4}\right)_{3}\right]$ tripalmitin, i.v. $\left[\mathrm{U}_{-}{ }^{13} \mathrm{C}_{16}\right]$ palmitate and $\left[{ }^{2} \mathrm{H}_{5}\right]$ glycerol) to evaluate chylomicron-TG and total triacylglycerol-rich lipoprotein (TRL)-TG kinetics. We used adipose tissue and skeletal muscle biopsies to evaluate the expression of genes regulating lipolysis and lipid oxidation, skeletal muscle respirometry to evaluate oxidative capacity, and indirect calorimetry to assess whole-body lipid oxidation.

Results The single bout of resistance exercise reduced the lipaemic response to a mixed meal in obese men with prediabetes without changing chylomicron-TG or TRL-TG fractional clearance rates. However, resistance exercise reduced endogenous and meal-derived fatty acid incorporation into chylomicron-TG and TRL-TG. Resistance exercise also increased whole-body lipid oxidation, skeletal muscle mitochondrial respiration, oxidative gene expression in skeletal muscle, and the expression of key lipolysis genes in adipose tissue.

Conclusions/interpretation A single bout of resistance exercise improves postprandial lipid metabolism in obese men with prediabetes, which may mitigate the risk for cardiovascular disease and type 2 diabetes.
\end{abstract}

Keywords Chylomicron · Lipid oxidation · Lipoprotein $\cdot$ Obesity $\cdot$ Postprandial $\cdot$ Prediabetes $\cdot$ Resistance exercise $\cdot$ Stable isotope tracer · VLDL

Electronic supplementary material The online version of this article (https://doi.org/10.1007/s00125-019-05070-x) contains peer-reviewed but unedited supplementary material, which is available to authorised users.

Adam J. Bittel

bittela@wusm.wustl.edu

1 Program in Physical Therapy, Washington University, St Louis, Campus Box 8502, 4444 Forest Park Ave., St Louis, MO 63110 , USA

2 Center for Human Nutrition, Washington University School of Medicine, St Louis, MO, USA

\begin{tabular}{ll}
\multicolumn{2}{l}{ Abbreviations } \\
1RM & One-repetition maximum \\
ATIRI & Adipose tissue insulin resistance index \\
CTRU & Clinical and Translational Research Unit \\
CVD & Cardiovascular disease \\
FCR & Fractional clearance rate \\
FOXO1 & Forkhead box protein O1 \\
iAUC & Incremental AUC \\
$R_{\mathrm{a}}$ & Rate of appearance \\
$R_{\mathrm{d}}$ & Rate of disappearance \\
TG & Triacylglycerol
\end{tabular}




\section{Research in context}

\section{What is already known about this subject?}

- Prediabetes is associated with postprandial dyslipidaemia, which increases the risk for cardiovascular disease and type 2 diabetes

- Endurance and resistance-type exercise acutely lower fasting and postprandial plasma triacylglycerol (TG) concentrations in men and women who are healthy, obese or have type 2 diabetes

- Aerobic exercise reduces postprandial TG by changing lipoprotein composition, and increasing lipoprotein clearance secondary to changes in lipoprotein affinity for lipoprotein lipase

\section{What is the key question?}

- What are the constitutive metabolic mechanisms underlying the changes in postprandial lipid metabolism after acute resistance exercise in overweight/obese men with prediabetes?

\section{What are the new findings?}

- A prior bout of acute resistance exercise reduces postprandial TG concentrations in obese men with prediabetes

- Acute resistance exercise reduces the incorporation of both meal-derived and endogenous plasma fatty acids into triacylglycerol-rich lipoprotein- and chylomicron-TGs

- Resistance exercise also increases postprandial whole-body lipid oxidation, skeletal muscle mitochondrial respiration, oxidative gene expression in skeletal muscle and the expression of key lipolysis genes in adipose tissue

How might this impact on clinical practice in the foreseeable future?

- This research provides mechanistic evidence to support the role of resistance exercise in the management of prediabetes, as well as the prevention of cardiovascular disease and type 2 diabetes in men with prediabetes

TRL Triacylglycerol-rich lipoprotein

TTR Tracer to tracee ratio

WUSTL Washington University in St Louis

\section{Introduction}

Sedentary behaviour is associated with dyslipidaemia and insulin resistance, type 2 diabetes and cardiovascular disease (CVD) [1-3]. There are also strong correlations between postprandial triacylglycerol (TG) concentrations and the risk of future cardiovascular events, as well as chylomicron remnant concentrations and the progression of coronary lesions, indicating that postprandial dyslipidaemia may be a potent contributor to CVD and a key target for treatment [4, 5]. Endurance and resistance-type exercise acutely lower fasting and postprandial plasma TG concentrations in men and women who are healthy, obese or have type 2 diabetes, and are part of the standard of care for patients with obesity, prediabetes, and type 2 diabetes [6-8]. However, these improvements may not be equivalent between men and women. There is evidence for sexual dimorphism in lipid metabolism in healthy individuals, with men demonstrating more pronounced postprandial lipaemia, but greater improvements in postprandial TG, lipid oxidation and resting metabolic rate after exercise than women [9-11]. Overall, the mechanisms of reduced postprandial lipaemia after a prior bout of exercise are incompletely understood.

Increased VLDL-TG and chylomicron-TG plasma clearance and oxidation play a central role in the reduction of postprandial TG after aerobic exercise $[12,13]$. Aerobic exercise has been shown to reduce VLDL-TG by increasing VLDL size (assessed as the VLDL-TG/VLDL-apolipoprotein B-100 ratio), which increases VLDL affinity for lipoprotein lipase (LPL) [12]. Moreover, using an isotopically labelled test meal, it was previously shown that aerobic exercise reduces endogenous, but not exogenous (meal-derived), TG concentrations in obese women [14]. It is unclear if aerobic exercise affects the TG content of chylomicron-TG, but it does not change chylomicron LPL affinity, which may explain why chylomicron concentrations do not change to the same extent as VLDL-TG after aerobic exercise $[12,15]$. In addition, since VLDL-TG secretion accounts for $18-20 \%$ of normal postprandial TG variation, changes in lipoprotein secretion (VLDL and/or chylomicrons) may also contribute to reduced postprandial lipaemia after aerobic exercise [16]. 
In contrast, much less is known about the effects of resistance exercise on postprandial lipid metabolism. In healthy, and metabolically normal, obese men and women, resistance exercise acutely (30 min post exercise) increases total postprandial NEFA oxidation, and augments VLDL-TG plasma clearance, but not secretion, after an overnight fast $[14,17]$. In men and women with type 2 diabetes, post-meal resistance exercise reduced postprandial plasma TG by reducing the VLDL-TG concentration [8]. In obese women, use of an isotopically labelled test meal demonstrated that resistance exercise increases exogenous postprandial lipid oxidation, reduces postprandial endogenous TG concentrations, and increases postprandial endogenous NEFA concentrations [14]. However, because a separate tracer was not used to track endogenous NEFA kinetics, measures of adipose tissue lipolysis, endogenous NEFA clearance or insulin resistance-key determinants of postprandial lipaemia-were not measured [18]. Moreover, chylomicrons and VLDL were not separated for tracer enrichment analysis, so it is not known if there are differential effects of resistance exercise on chylomicron vs VLDL handling or clearance.

Therefore, we aimed to perform a comprehensive analysis of postprandial lipid metabolism following an acute bout of resistance exercise in overweight/obese men with prediabetes. Using a novel approach employing three stable isotope tracers, we hypothesised that resistance exercise would reduce postprandial TG levels by improving insulin sensitivity (which may reduce adipose tissue lipolysis and reduce NEFA release into the plasma), reducing lipoprotein endogenous and exogenous NEFA concentrations in triacylglycerol-rich lipoprotein (TRL)-TG, increasing whole-body and skeletal muscle mitochondrial lipid oxidation to augment lipoprotein and NEFA clearance, and increasing the expression of genes regulating lipolysis and lipid oxidation in adipose tissue and skeletal muscle.

\section{Methods}

\section{Participants}

Participants were recruited from Washington University in St Louis (WUSTL) School of Medicine Diabetes Clinic, the WUSTL Volunteers for Health, the Center for Community Based Research databases, and advertising in the St Louis metropolitan area from August 2015 to May 2018. Potential participants completed a detailed screening evaluation including a history and physical examination, serum blood chemistries $\left(\mathrm{HbA}_{1 \mathrm{c}}\right.$, a lipid panel, a comprehensive metabolic panel and a complete blood count) and an OGTT (see electronic supplementary material (ESM) Methods for further details). Participants were included if they were male, aged 30-65 years with a BMI of $28-45 \mathrm{~kg} / \mathrm{m}^{2}$, and met the criteria for prediabetes $\left(\mathrm{HbA}_{1 \mathrm{c}}>38\right.$ but $<48 \mathrm{mmol} / \mathrm{mol}[>5.7 \%$ but $<6.5 \%]$ ), or fasting plasma glucose $>5.6 \mathrm{mmol} / \mathrm{l}$ but $<7.0 \mathrm{mmol} / \mathrm{l}$, or $2 \mathrm{~h}$ OGTT glucose
$>7.8 \mathrm{mmol} / \mathrm{l}$ but $<11.1 \mathrm{mmol} / \mathrm{l}$ ) [19]. Participants were excluded if they were diagnosed with type 2 diabetes, used insulin or other blood-sugar-lowering medications, had participated in regular exercise ( $\geq 2$ times/week) within the previous 6 months (assessed by questionnaire during the initial phone interview), had a history of pulmonary or CVD, coagulation disorders, anaemia or had an orthopaedic, neurological, metabolic or other medical condition that would prohibit them from participating in the exercise and metabolic testing protocol. Participants also completed a onerepetition maximum (1RM) strength assessment, daily physical activity monitoring, and body composition measurements using dual x-ray absorptiometry (DXA, see ESM Methods for further details). The study was approved by the WUSTL Human Research Protection Office (protocol no. 20160495) and all participants provided written informed consent prior to enrolment. All procedures were completed in accordance with the ethical principles outlined in the Declaration of Helsinki.

\section{Participant demographics}

Participants had a mean age of 50 years, were obese and demonstrated insulin resistance with compensatory increases in beta cell function. Participants also presented with elevated mean total triacylglycerol and LDL-cholesterol concentrations and a low HDL-cholesterol concentration, and were sedentary for the majority of the day (Table 1).

\section{Study protocol}

Lipid metabolism study Each participant completed two lipid metabolism studies (exercise and rest) in randomised order, approximately 1 week apart (Fig. 1). Treatment order (rest or exercise) was assigned through simple random sampling without replacement (see Electronic supplementary material (ESM) Methods). Between studies, participants were instructed to maintain their normal diet and daily activity level. During the exercise study, participants completed a $1 \mathrm{~h}$ bout of whole-body resistance exercise $270 \mathrm{~min}$ before meal ingestion; for the rest study, participants rested in a chair for $1 \mathrm{~h}$.

The day prior to each lipid metabolism study, participants were provided a standardised breakfast $(2.18 \mathrm{MJ})$, lunch (3.02 MJ), afternoon snack (0.75 MJ), and dinner (3.26 MJ) from the WUSTL Clinical and Translational Research Unit (CTRU) Bionutrition Service. They consumed a liquid formula (Ensure; Ross Laboratories, Columbus, OH, USA) containing 1.05 $\mathrm{MJ}$ at $\sim 22: 00$ hours to ensure complete filling of hepatic glycogen stores. The carbohydrate, fat and protein contents for each meal are provided in the ESM. Participants then fasted overnight $(10 \mathrm{~h})$ except for water and reported to the CTRU at 07:30 hours the following morning. After admission, an i.v. catheter was inserted into the antecubital vein to collect baseline blood samples and for later tracer infusions. 
Table 1 Participant demographics

\begin{tabular}{lc}
\hline Measure & Mean (SD) \\
\hline Age (years) & $50(9)$ \\
Height (cm) & $178(6)$ \\
Weight $(\mathrm{kg})$ & $105(12)$ \\
BMI $\left(\mathrm{kg} / \mathrm{m}^{2}\right)$ & $33(3)$ \\
Fat mass $(\mathrm{kg})$ & $33(6.4)$ \\
Lean mass $(\mathrm{kg})$ & $67(6.2)$ \\
Body fat $(\%)$ & $31.6(4)$ \\
HbA $1 \mathrm{c}(\mathrm{mmol} / \mathrm{mol})$ & $39(3.4)$ \\
HbA $1 \mathrm{c}(\%)$ & $5.7(0.5)$ \\
Fasting glucose $(\mathrm{mmol} / \mathrm{l})$ & $5.9(0.7)$ \\
2-h OGTT glucose (mmol/l) & $9.1(0.5)$ \\
Fasting insulin (pmol/l) & $3.2(0.86)$ \\
HOMA2-IR & $2.6(1.2)$ \\
HOMA2-\%B & $139.4(56)$ \\
HOMA2-\%S & $46(16)$ \\
Triacylglycerol (mmol/l) & $1.9(0.27)$ \\
Total cholesterol (mmol/l) & $4.8(0.83)$ \\
HDL-cholesterol (mmol/l) & $0.99(0.13)$ \\
LDL-cholesterol (mmol/l) & $3.0(0.75)$ \\
Time sedentary (\%) & $69(19.2)$ \\
Time light activity (\%) & $21(11.4)$ \\
Time moderate activity (\%) & $10(9.5)$ \\
Time vigorous activity $(\%)$ & $0(0)$ \\
\hline & \\
\hline
\end{tabular}

Times spent in each activity were derived from accelerometry data (see ESM methods). $2 \mathrm{~h}$ OGTT is plasma glucose at $2 \mathrm{~h}$ after a $75 \mathrm{~g}$ oral glucose challenge. HOMA2 was calculated using the HOMA2 calculator (see ESM methods). HOMA2-\%B, HOMA2 of steady state beta cell function; HOMA2-\%S, HOMA2 of insulin sensitivity

During the rest period, participants rested quietly in the semi-recumbent position for $60 \mathrm{~min}$ from 09:00 hours to 10:00 hours. During the exercise study, participants performed
$1 \mathrm{~h}$ (from 09:00 hours to 10:00 hours) of resistance exercise consisting of three sets of $10-12$ repetitions at $80 \%$ of $1 \mathrm{RM}$ of the following seven exercises: leg press, knee extension, chest press, shoulder press, seated row, pull down and bicep curl (See ESM).

Following the rest or resistance exercise period, a second catheter was inserted into a hand vein on the contralateral arm; the hand was warmed with a warming box $\left(55^{\circ} \mathrm{C}\right)$ to collect arterialised blood samples. To allow time for catheter insertion, the study timer was started (study time 0) $30 \mathrm{~min}$ post exercise or post rest. At $60 \mathrm{~min}$, a constant infusion of [U- ${ }^{13} \mathrm{C}_{16}$ ]palmitate $\left(5.3 \mathrm{nmol} \mathrm{kg}{ }^{-1} \mathrm{~min}^{-1}\right)$ bound to human albumin was initiated and continued until the end of the study. At 180 min, participants were given a liquid meal (Boost Plus; Fremont, MI, USA) consisting of $0.08 \mathrm{MJ} / \mathrm{kg}$ fat-free mass ( $47.8 \%$ carbohydrate, $36.1 \%$ fat, and $16.1 \%$ protein). $\left[1,1,1,2,2,2,3,3,3,4,4,4-\left({ }^{13} \mathrm{C}_{4}\right)_{3}\right]$ Tripalmitin was added to the test meal and thoroughly mixed. A description of meal preparation is included in the ESM. At $210 \mathrm{~min}$, a $75 \mu \mathrm{mol} / \mathrm{kg}$ body weight bolus of $\left[1,1,2,3,3-{ }^{2} \mathrm{H}_{5}\right]$ glycerol was administered by injection to the final seven participants who completed the study. Blood samples were collected at $-10,160,170,180$, 196, 210, 215, 225, 240, 270, 300, 330, 360, 420, 480 and $540 \mathrm{~min}$ (Fig. 1). All stable isotope tracers were obtained from Cambridge Isotope Laboratories (Tewksbury, MA, USA).

At $270 \mathrm{~min}$ (90 min post meal), biopsy samples were obtained from the vastus lateralis muscle and abdominal subcutaneous adipose tissue. The whole-body lipid oxidation rate was measured at baseline ( $-90 \mathrm{~min})$, immediately before the resistance exercise/rest period and at 140, 210, 240, 330, 390,450 and 510 min using indirect calorimetry, as previously described [20].

Sample processing Methods for isolating TRL and chylomicron fractions, and measuring palmitate and glycerol

Fig. 1 Study protocol

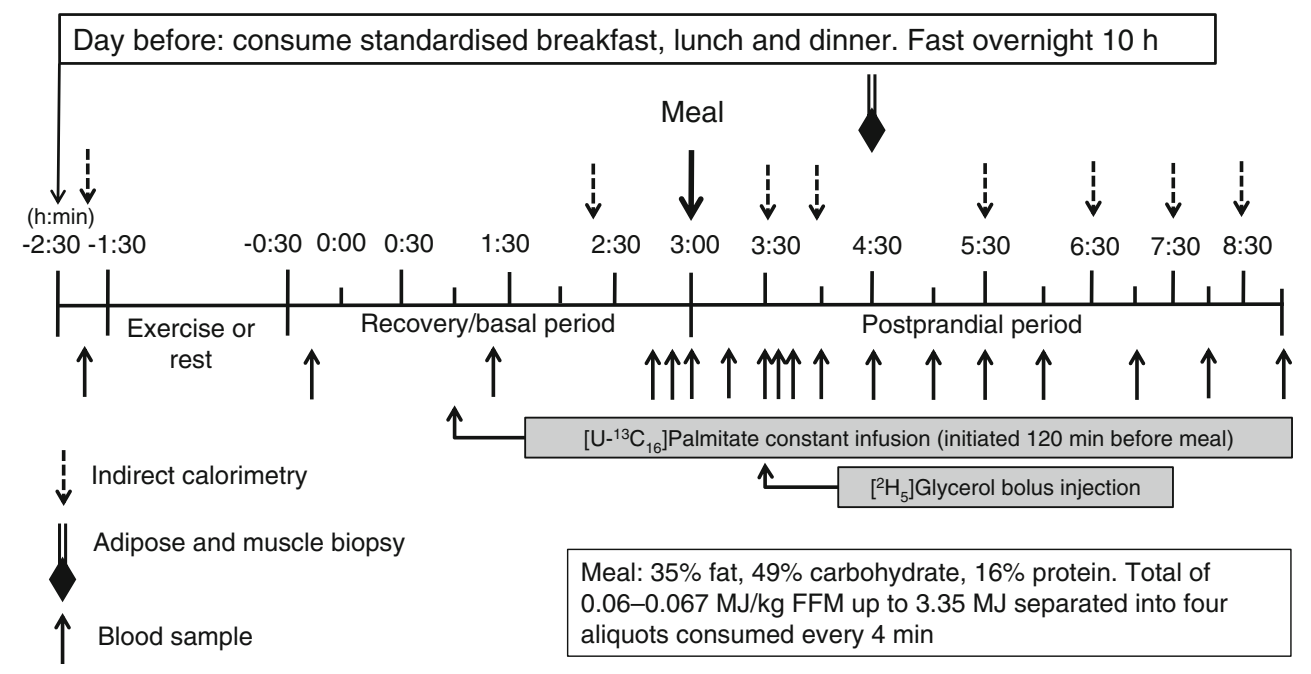


enrichments are described in the ESM Methods. Total plasma, TRL, and chylomicron-TG concentrations were measured using a colorimetric assay (Wako Diagnostics, Richmond VA, USA). VLDL-TG concentrations were measured by subtracting chylomicron-TG concentration from TRL-TG concentration. Plasma insulin was measured using electrochemiluminescence immunoassay (Elecsys, Roche Diagnositics, Mannheim, Germany). Plasma glucose was measured using the glucose oxidase method (Yellow Springs Instrument, Yellow Springs, OH, USA).

Tissue biopsies, mitochondrial respiration and RT-qPCR Biopsy samples from the vastus lateralis muscle and abdominal subcutaneous adipose tissue were collected under local anaesthesia as previously described [21, 22]. A 6-10 mg sample of skeletal muscle was used for mitochondrial highresolution respirometry analysis (Oxygraph-2k, Oroboros Instruments, Innsbruck, Austria; see ESM methods and ESM Tables 1 and 2). Remaining muscle and adipose tissue samples were irrigated with saline $(150 \mathrm{mmol} / \mathrm{l} \mathrm{NaCl})$, flash frozen in liquid nitrogen and stored at $-80^{\circ}$ until analysis. Gene expression was determined using RT-qPCR (see ESM methods and ESM Table 3). Data were $\log _{2}$-transformed for statistical analyses and back-transformed for presentation.

Calculations The concentrations of $\left[{ }^{13} \mathrm{C}_{4}\right]$ palmitate and [U- ${ }^{13} \mathrm{C}_{16}$ ]palmitate in TRL-TG, chylomicron-TG, and plasma palmitate were calculated using palmitate concentration and tracer enrichments in the respective pools (see ESM Methods). Basal (fasted) palmitate rate of appearance $\left(R_{\mathrm{a}}\right)$ into plasma was calculated by dividing the tracer infusion rate by the plasma palmitate tracer to tracee ratio (TTR) [23]. The basal adipose tissue insulin resistance index (ATIRI) was calculated as the product of basal palmitate $R_{\mathrm{a}}$ and plasma insulin concentration [23].

The total AUC was calculated using the trapezoid rule [24]; incremental AUCs (iAUCs) were obtained after adjusting for basal values [24]. Fractional clearance rates (FCR) of TRLTG and chylomicron-TG were determined using the monoexponential decay rate of $\mathrm{TG}^{2} \mathrm{H}_{5}$-glycerol from 2-6 h after the start of the meal (1.5-5.5 h after the bolus of ${ }^{2} \mathrm{H}_{5^{-}}$ glycerol tracer) as previously described [25].

Statistical analysis Differences in outcome measures between rest and exercise were assessed using repeated measures ANOVA with treatment (rest/RE) and time (before/after meal) entered as repeated factors, and order (rest $>\mathrm{RE}$ or RE $>$ rest) as a between-subjects factor. Significant interactions between treatment and time were further analysed using paired $t$ tests. The Benjamini-Hochberg procedure was used to control for multiple comparisons for all repeated measures. AUCs, respiration, lipid oxidation and gene expression measures were analysed using paired $t$ tests (if normally distributed) or the Wilcoxon signed- rank test (if non-normally distributed) between rest and exercise. An $\alpha$ level of 0.05 was used for significance. Cohen's $d$ (paired $t$ tests), $r$ (Wilcoxon signed-rank tests) and partial $\eta 2$ (repeated measures ANOVA) were used to calculate effect size. Previous studies have reported effect sizes ranging from 0.78 (reduced plasma TG by $14-24 \%$ ) to 1.85 for the impact of resistance exercise on postprandial triacylglycerol concentrations [7, 26]. Based on these findings, using an effect size of 1.0, we determined a sample size of ten participants was needed to detect a significant treatment effect at a two-tailed $\alpha$ level of $<0.05$ with $80 \%$ power (See ESM Statistical Analysis and Sample Size Determination). All analyses were completed in SPSS version 25 (IBM, Armonk, NY, USA) on all ten participants unless otherwise specified.

\section{Results}

\section{Basal period NEFA kinetics and insulin resistance}

Basal (fasted state prior to the meal test) plasma fatty acid concentrations, palmitate rates of appearance $\left(R_{\mathrm{a}}\right)$ and disappearance $\left(R_{\mathrm{d}}\right)$, and ATIRI were not significantly different between rest and resistance exercise (Table 2).

\section{Postprandial total plasma triacylglycerol, NEFA and insulin concentration}

Changes in chylomicron-TG, VLDL-TG, TRL-TG, total plasma TG, plasma NEFA and plasma free palmitate are shown in Fig. 2. Although there was no statistically significant difference in plasma TG concentration after rest and resistance exercise at any given time point, the postprandial iAUC for chylomicron-TG, and TRL-TG concentrations were significantly lower after resistance exercise than after rest (Table 2). The iAUC was also significantly reduced after resistance exercise for total plasma TG. VLDL-TG concentration iAUC was not lower after resistance exercise than rest (Table 2). The postprandial plasma NEFA concentration iAUC following resistance exercise was not significantly different to that after rest; however, the plasma insulin concentration iAUC was significantly lower after resistance exercise than after rest (Table 2).

\section{Meal-derived postprandial lipid tracer concentration}

Meal-derived $\left[{ }^{13} \mathrm{C}_{4}\right]$ palmitate enrichment and concentration in chylomicron-TG, VLDL-TG and TRL-TG, and the plasma free palmitate pool were quantified throughout the postprandial period to determine meal-derived (exogenous) lipid handling. $\left[{ }^{13} \mathrm{C}_{4}\right]$ palmitate concentration in chylomicron-TG (treatment $\times$ time interaction, $p=0.014$, partial $\eta^{2}=0.23$ ) and TRL-TG (main effect of treatment, $p=0.044$, partial $\left.\eta^{2}=0.17\right)$ were significantly lower after resistance exercise 
than rest (Fig. 3a,c). $\left[{ }^{13} \mathrm{C}_{4}\right]$ Palmitate TTR (ESM Fig. 1c) and concentration (Fig. 3d) in the plasma free palmitate pool, and the $\left[{ }^{13} \mathrm{C}_{4}\right]$ palmitate concentration in VLDL-TG (Fig. 3b) was not significantly different between the resistance exercise and rest conditions. The $\left[{ }^{13} \mathrm{C}_{4}\right]$ palmitate TTR was not different after resistance exercise in chylomicron-TG or TRL-TG (ESM Figure 1a,b). Total AUC for exogenous palmitate concentration in chylomicron-TG $(p=0.039, d=0.85)$ and TRL-TG ( $p=0.036, d=0.78$ ) was significantly lower following resistance exercise compared with rest (Fig. 3a,c).

\section{Infused postprandial lipid tracer concentrations}

$\left[\mathrm{U}_{-}{ }^{13} \mathrm{C}_{16}\right]$ Palmitate TTR and concentration in chylomicronTG, VLDL-TG and TRL-TG, and the plasma free palmitate pool were quantified throughout the postprandial period to evaluate utilisation of plasma fatty acids. $\left[\mathrm{U}_{-}{ }^{13} \mathrm{C}_{16}\right]$ Palmitate TTR in chylomicron-TG (ESM Fig. 1d, main effect of treatment, $p=0.010$, partial $\left.\eta^{2}=0.62\right)$, $\left[\mathrm{U}_{-}{ }^{13} \mathrm{C}_{16}\right]$ palmitate concentration in chylomicron-TG (Fig. 4a, interaction treatment $\times$ time, $p=0.004$, partial $\eta^{2}=0.32$ ), and $\left[\mathrm{U}_{-}{ }^{13} \mathrm{C}_{16}\right.$ ]palmitate concentration in TRL-TG (Fig. 4c, interaction treatment $\times$ time, $p=0.020$, partial $\eta^{2}=0.28$ ) was significantly lower after resistance exercise than after rest. The $\left[\mathrm{U}_{-}{ }^{13} \mathrm{C}_{16}\right]$ palmitate concentration in VLDL-TG (Fig. 4b, $p=0.22$ ) was not significantly different between the rest and resistance exercise conditions. The $\left[\mathrm{U}_{-}{ }^{13} \mathrm{C}_{16}\right]$ palmitate TTR was not different between rest and resistance exercise for TRL-TG or plasma free palmitate (ESM Fig. 1e,f).
However, the AUC for $\left[\mathrm{U}_{-}^{13} \mathrm{C}_{16}\right]$ palmitate TTR (ESM Fig. $1 \mathrm{~d}, p=0.012, d=1.06)$ and the AUC for $\left[\mathrm{U}_{-}{ }^{13} \mathrm{C}_{16}\right]$ palmitate concentration in chylomicron-TG (Fig. $4 \mathrm{a}, p=0.008, d=$ 1.10) was lower following resistance exercise than after rest, as was the AUC for $\left[\mathrm{U}_{-}^{13} \mathrm{C}_{16}\right]$ palmitate concentration in TRLTG (Fig. 4c, $p=0.014, d=0.963$ ). The AUC for $\left[\mathrm{U}_{-}{ }^{13} \mathrm{C}_{16}\right.$ ]palmitate concentration in VLDL-TG (Fig. $4 \mathrm{~b}, p=$ 0.16 ) and in plasma NEFA (Fig. $4 \mathrm{~d}, p=0.89$ ) were not significantly different between the resistance exercise and rest conditions. The lack of a difference in the postprandial free [U- ${ }^{13} \mathrm{C}_{16}$ ]palmitate TTR (ESM Fig. 1f) or the plasma palmitate concentration ( $p=0.63$, Fig. $2 \mathrm{f}$ ) between rest and resistance exercise indicates that there was no significant difference in the postprandial plasma palmitate $R_{\mathrm{a}}$ between conditions.

\section{Postprandial lipoprotein FCR}

The FCR for TRL-TG $(p=0.21)$ and chylomicron-TG $(p=$ 0.34 ) were not significantly different between the resistance exercise and rest conditions (Table 2).

\section{Lipid oxidation}

The whole-body lipid oxidation rate was significantly elevated (significant interaction treatment $\times$ time $p=0.004$, partial $\left.\eta^{2}=0.34\right)$ at 140,210 , and $330 \mathrm{~min}$ after resistance exercise compared with after rest (Fig. 5a). The lipid oxidation AUC

Table 2 Postprandial iAUC, basal NEFA kinetics and postprandial lipoprotein kinetics

\begin{tabular}{|c|c|c|c|c|}
\hline Measure & Rest & Exercise & $p$ value & Effect size \\
\hline Basal NEFA concentration (mmol/l) & $0.91[0.65-2.75 ; 0.42]$ & $0.88[0.45-1.83 ; 0.40]$ & 0.44 & 0.17 \\
\hline Basal palmitate concentration (mmol/l) & $0.24[0.16-0.67 ; 0.05]$ & $0.22[0.14-0.43 ; 0.16]$ & 0.57 & 0.13 \\
\hline Basal palmitate $R_{\mathrm{a}}\left(\mu \mathrm{mol}[\mathrm{kg} \mathrm{FM}]^{-1} \min ^{-1}\right)$ & $5.3(1.7)$ & $6.5(2.4)$ & 0.15 & 0.57 \\
\hline Basal palmitate $R_{\mathrm{d}}\left(\mu \mathrm{mol}[\mathrm{kg} \mathrm{FFM}]^{-1} \min ^{-1}\right)$ & $2.4[1.5-4.6 ; 1.6]$ & $2.5[1.9-7.1 ; 2.2]$ & 0.16 & 0.31 \\
\hline Basal ATIRI $(\mu \mathrm{mol} / \mathrm{min} \times \mathrm{pmol} / \mathrm{l})$ & $394(231)$ & $454(215)$ & 0.41 & 0.24 \\
\hline Postprandial chylomicron-TG iAUC $(\mathrm{mmol} / 1 \times 360 \mathrm{~min})$ & $43.9[18.4-174.9 ; 77.8]$ & $33.5[21.4-140.7 ; 38.8]$ & 0.02 & 0.51 \\
\hline Postprandial VLDL-TG iAUC $(\mathrm{mmol} / 1 \times 360 \mathrm{~min})$ & $100(85)$ & $59(79)$ & 0.06 & 0.68 \\
\hline Postprandial TRL-TG iAUC (mmol/1 × 360 min) & $126.6[51.1-346.4 ; 157.2]$ & $96.3[-20-295.7 ; 92.5]$ & 0.01 & 0.58 \\
\hline Postprandial plasma NEFA iAUC $(\mathrm{mmol} / 1 \times 360 \mathrm{~min})$ & $-113[-195--25 ; 79]$ & $-79[-432--40 ; 81]$ & 0.96 & 0.01 \\
\hline Postprandial total plasma TG iAUC $(\mathrm{mmol} / 1 \times 360 \mathrm{~min})$ & $135[26.8-354.3 ; 174]$ & $97.9[23.3-318.1 ; 185.2]$ & 0.01 & 0.63 \\
\hline Postprandial plasma palmitate iAUC $(\mathrm{mmol} / 1 \times 360 \mathrm{~min})$ & $-30(16)$ & $-35(30)$ & 0.61 & 0.19 \\
\hline Postprandial plasma insulin iAUC (pmol/1 × $360 \mathrm{~min})$ & $4108(924)$ & $3282(1187)$ & 0.03 & 0.83 \\
\hline Postprandial TRL-TG FCR (pools/h) & $0.25(0.17)$ & $0.33(0.19)$ & 0.21 & 0.46 \\
\hline Postprandial chylomicron-TG FCR (pools/h) & $0.42(0.22)$ & $0.49(0.21)$ & 0.34 & 0.32 \\
\hline
\end{tabular}

Data are presented as mean $( \pm \mathrm{SD})$ for normally distributed data, or median [minimum-maximum; interquartile range] for non-normally distributed data. ATIRI, higher $=$ more insulin resistant. FM, fat mass. FFM, fat-free mass. Chylo, chylomicron. FCR calculations were made from $n=7$ participants (see Methods). The iAUC is negative for postprandial plasma NEFA, representing the area above the curve extending up to the baseline (180 min) value as an index of postprandial NEFA suppression. Basal NEFA and palmitate concentration is the concentration at 180 min. Significant difference between rest and exercise if $p<0.05$ for paired $t$ tests (parametric) or Wilcoxon signed-rank test (non-parametric). Effect sizes are calculated using Cohen's $d$ (paired $t$ tests) or $r$ (Wilcoxon signed-rank test) 
Fig. 2 TG and NEFA

concentration time courses. (a-f)

Postprandial TG concentrations in the rest and resistance exercise conditions for chylomicron-TG (a), VLDL-TG (b), TRL-TG (c), total plasma TG (d), plasma NEFA (e) and plasma free palmitate (f). (g) Plasma insulin concentration is shown in in the rest and resistance exercise conditions. Values are mean \pm $\operatorname{SEM}(n=10)$
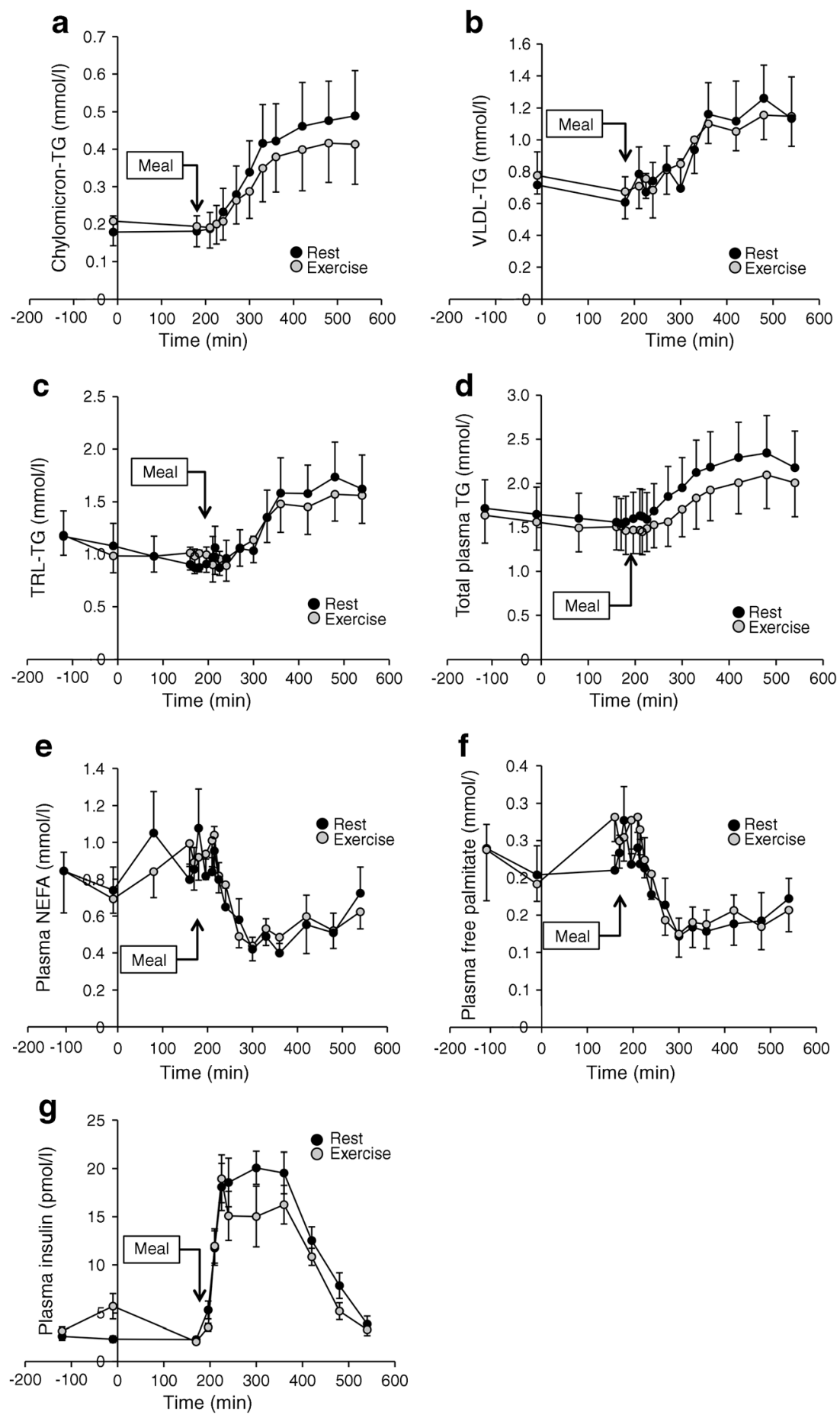

was significantly greater after resistance exercise than after rest ( $p=0.049, d=0.69)$ (Fig. 5b).

\section{Skeletal muscle mitochondrial respiration}

Muscle biopsies were obtained from eight participants. A representative trace of mitochondrial respiration is shown in Fig. 5c. Maximal lipid oxidation $(p=0.004, d=1.46)$, complex I-supported lipid + pyruvate oxidation $(p=0.003$, $d=1.53$ ), oxidative phosphorylation through complex I and II ( $p=0.005, d=1.38)$, electron transport capacity $(p=0.017$, $d=1.09)$ and complex II-supported respiration $(p=0.022$, $d=1.03$ ) rates were higher following resistance exercise compared with rest (Fig. 5d). Leak respiration was not significantly different between conditions $(p=0.260)$ (Fig. $5 \mathrm{~d})$. Oxidative phosphorylation control ratio and respiratory control ratio was significantly higher following resistance exercise compared with the rest condition; however, the 

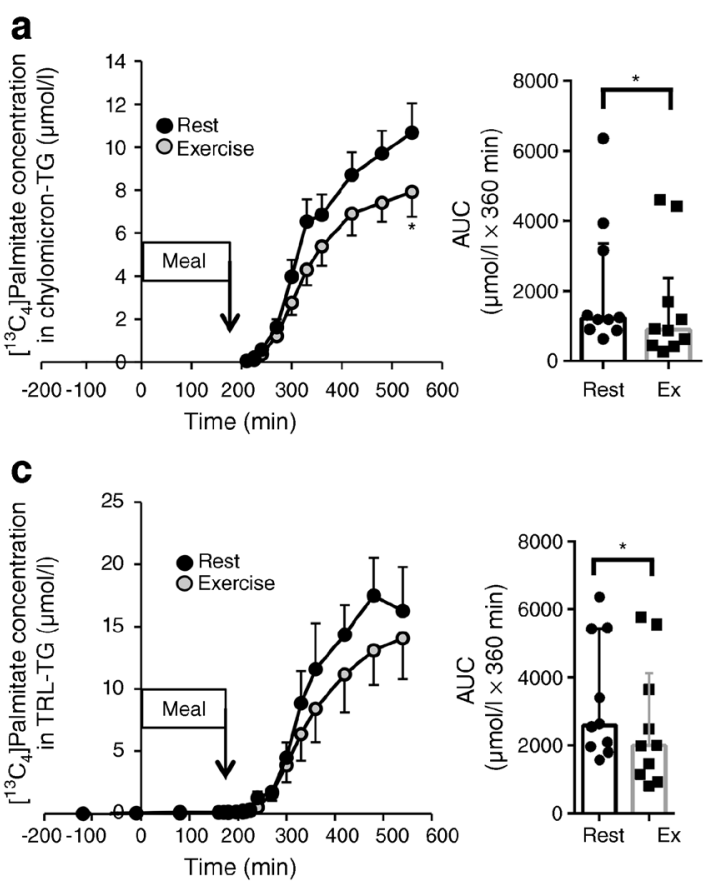

Fig. 3 Meal-derived lipid tracer metabolism. The $\left[{ }^{13} \mathrm{C}_{4}\right]$ palmitate concentration is shown for chylomicron-TG (a), VLDL-TG (b), TRLTG (c) and in plasma NEFA (d) $(n=10)$. The corresponding AUC (median \pm interquartile range) for the concentration data are shown in the bar graph immediately to the right in $(\mathbf{a}-\mathbf{d})(n=10)$. 'Meal' indicates timing
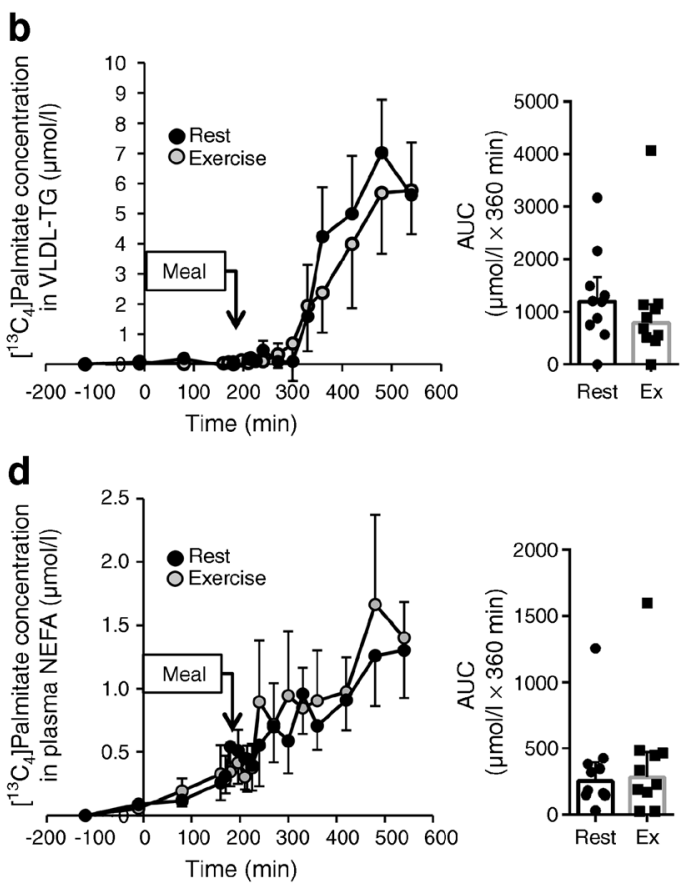

of mixed meal consumption. Time course values are mean \pm SEM. * Denotes a time point significantly different between rest and exercise (time course data, repeated measures ANOVA) or a significant difference between rest and exercise for tracer concentration AUC (Wilcoxon signed-rank test) $(p<0.05)$
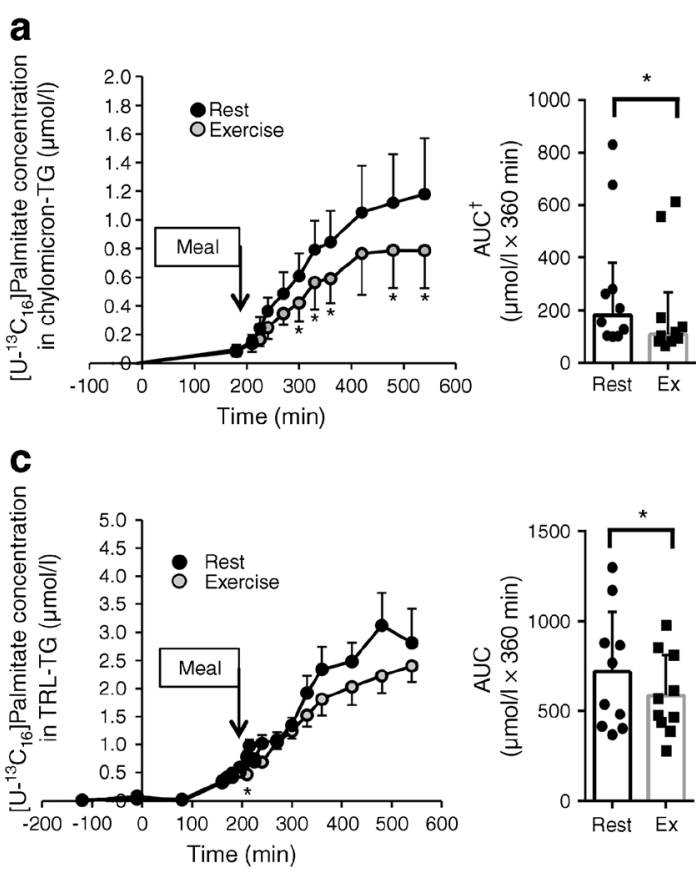

Fig. 4 Infused lipid tracer metabolism. The $\left[\mathrm{U}_{-}{ }^{13} \mathrm{C}_{16}\right]$ palmitate concentration is shown for chylomicron-TG (a), VLDL-TG (b), TRL-TG (c), and in plasma NEFA $(\mathbf{d})(n=10)$. The corresponding AUC (mean \pm SD unless otherwise noted) for the concentration data are shown in the bar graph immediately to the right in (a-d). 'Meal' indicates timing of mixed meal consumption. Time course values are mean \pm SEM. $*$ Denotes time b

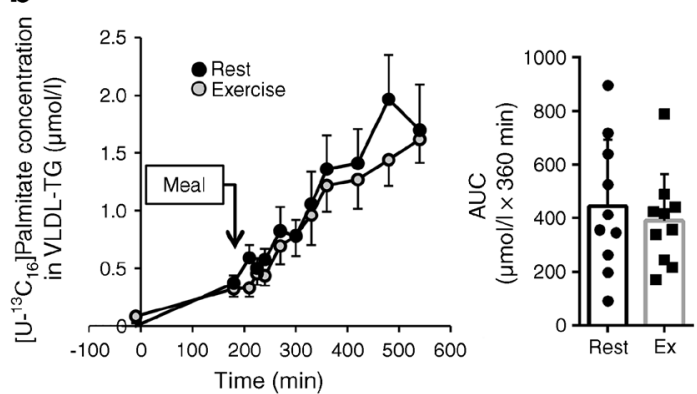

d
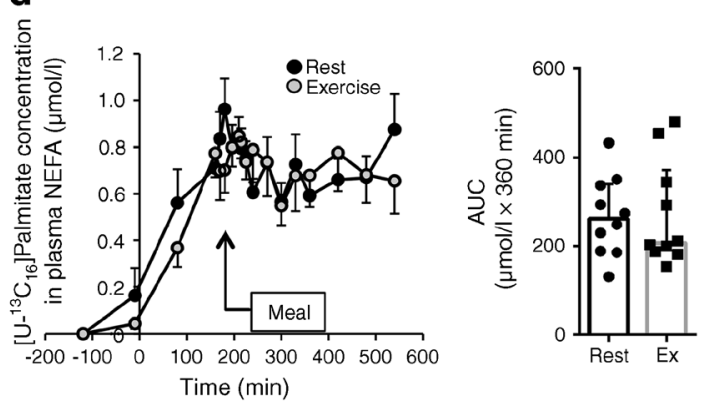

point significantly different between rest and exercise (time course data), or a significant difference between rest and exercise for tracer concentration AUC (paired $t$ test for normally distributed data or Wilcoxon signedrank test for non-normally distributed data) $(p<0.05) .{ }^{\dagger}$ Denotes use of median \pm interquartile range for non-normally distributed data 

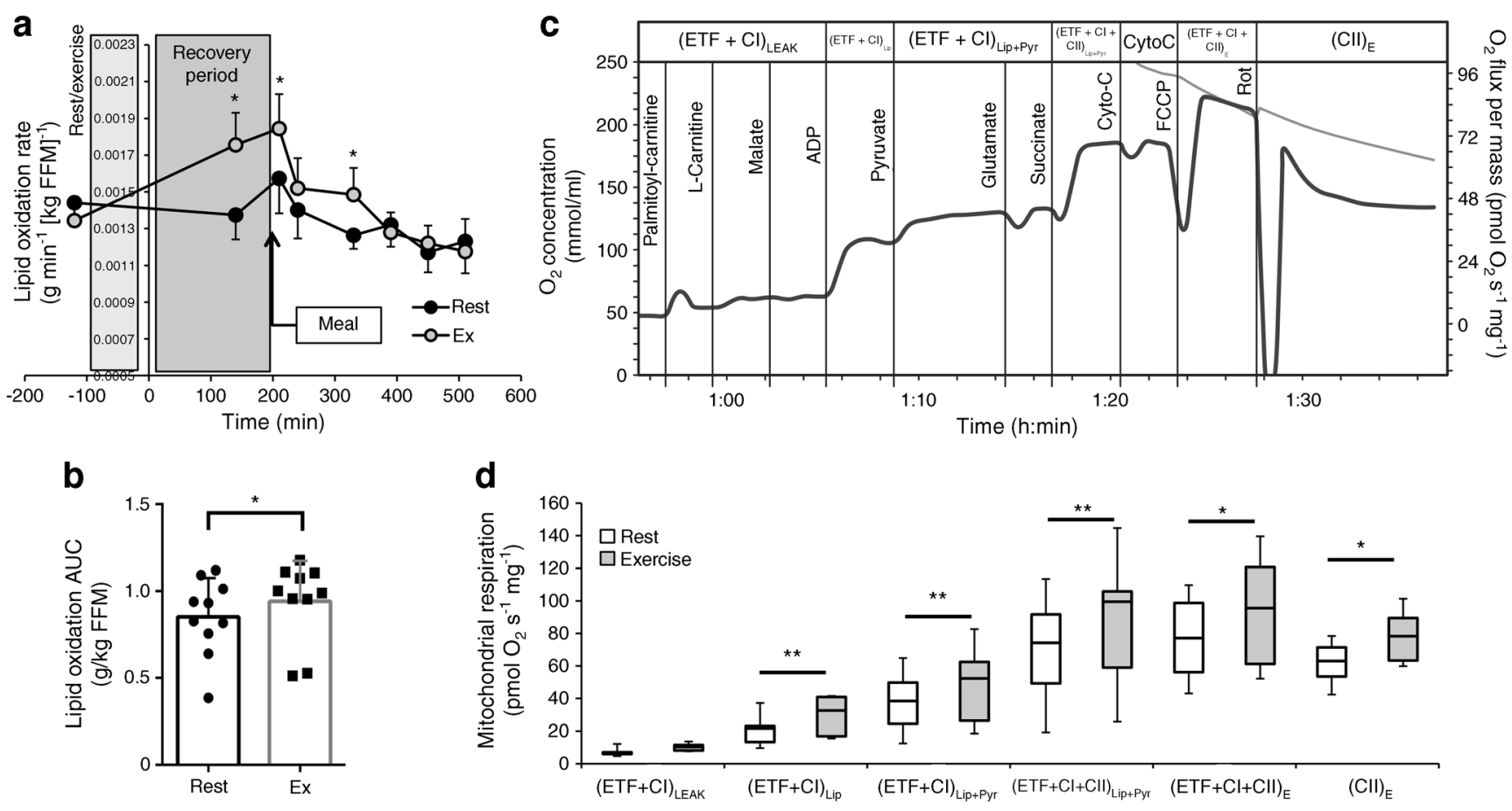

Fig. 5 Changes in lipid oxidation after resistance exercise. (a) Lipid oxidation rate $\left(\mathrm{g} \mathrm{min}^{-1}[\mathrm{~kg} \mathrm{FFM}]^{-1}\right.$, mean $\left.\pm \mathrm{SEM}\right)$ in the rest and exercise conditions. 'Meal' indicates timing of mixed meal consumption. Grey box labelled 'Rest/exercise' denotes timing of the rest or exercise session. Box labelled 'Recovery period' denotes timing of the 180 min recovery period. There was a significant interaction between treatment and time for lipid oxidation rate (see Results for details). (b) AUC (from -120 to $540 \mathrm{~min}$, mean $\pm \mathrm{SD}$ ) for total lipid oxidation in the rest and exercise conditions. (c) An example of a respiration curve recorded from permeabilised muscle fibres from the vastus lateralis. Vertical lines denote the timing of substrate titrations. The substrate added at each time point is listed to the left of each line. Subsequent substrates were added only after

$\mathrm{O}_{2}$ flux reached a plateau as shown. Respiratory states are listed along the top. For corresponding definitions, see ESM Table 1. (d) Box plots displaying oxygen consumption for the respiratory states assessed using the substrate-uncoupler-inhibitor titration (SUIT) protocol (see ESM Table 1). Resistance exercise significantly increased complex I-supported lipid $\left[(\mathrm{ETF}+\mathrm{CI})_{\mathrm{Lip}}\right]$ and lipid + pyruvate respiration $\left[(\mathrm{ETF}+\mathrm{CI})_{\mathrm{Lip}+\mathrm{Pyr}}\right]$, as well as lipid + pyruvate respiration through complexes I and II [(ETF + $\left.\mathrm{CI}+\mathrm{CII})_{\mathrm{Lip}+\mathrm{Pyr}}\right]$, maximal electron transport capacity $\left[(\mathrm{ETF}+\mathrm{CI}+\mathrm{CII})_{\mathrm{E}}\right]$ (uncoupled respiration) and complex II-supported respiration $\left[(\mathrm{CII})_{\mathrm{E}}\right]$ (measured after inhibition of complex I with rotenone). ETF, electron transfer flavoprotein. * Denotes significantly different than rest at $p<0.05, * * p<0.01,(n=10)$

phosphorylation control ratio and the leak control ratio were not different between resistance exercise and rest (ESM Table 4). Complex I-supported lipid respiration normalised to maximal oxidative phosphorylation, complex I-supported lipid respiration normalised to maximal electron transport capacity, the lipid to glucose oxidation ratio, and the free oxidative phosphorylation capacity were significantly higher following resistance exercise than following rest (ESM Table 4).

\section{Skeletal muscle and adipose tissue gene expression}

Total RNA was isolated from muscle biopsy samples from eight participants. However, RNA in one sample was degraded; therefore, data were analysed from samples for qPCR analysis for seven participants only. PPARGC1A $(p=0.010, d=1.49)$, PDK4 ( $p=0.008, d=1.54)$, FOXO1 $(p=0.037, d=0.98)$ and MURF1 (also known as TRIM63, $p=0.002, d=1.63$ ) expression in skeletal muscle was significantly higher following resistance exercise compared with rest (Fig. 6a). $L P L$ expression in skeletal muscle was higher after resistance exercise compared with after rest, but it did not reach statistical significance $(p=$ 0.064) (Fig. 6a). SREBF1 expression in skeletal muscle was significantly lower after resistance exercise than after rest ( $p=0.020, d=1.23$ ) (Fig. 6a). Expression of skeletal muscle $F A S N$, ACACA, CD36, and CPT1A were not significantly different between conditions (not shown).

Abdominal subcutaneous tissue biopsies were collected from six participants. Adipose FOXO1 $(d=1.47)$, PDK4 $(d=1.57), L P L(d=1.04), H S L(d=1.95)$ and adiponectin $A D I P O Q(d=1.41)$ expression was significantly higher following exercise than following rest (all $p<0.05$, Fig. $6 \mathrm{~b}$ ). Adipose tissue CD36 expression was not changed ( $p=0.068$ ) following resistance exercise compared with following rest (Fig. 6b). Adipose triglyceride lipase (ATGL) expression $(p=0.110)$, likewise, was not significantly different between conditions (Fig. 6b). 


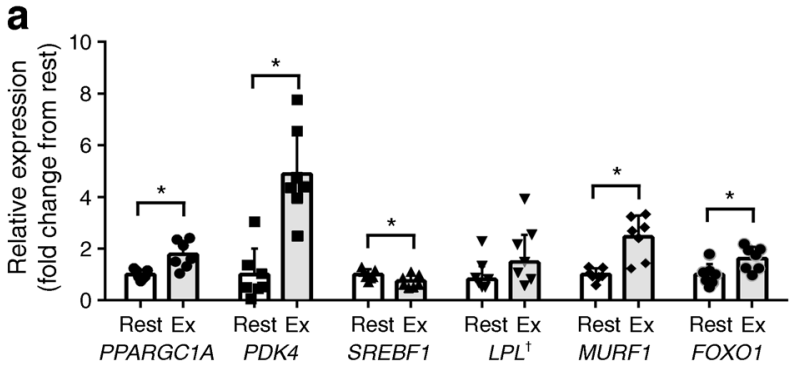

Fig. 6 Skeletal muscle and abdominal subcutaneous adipose tissue gene expression. (a) Resistance exercise significantly increased skeletal muscle expression of PPARGC1A, PDK4, FOXO1 and MURF1, and non-significantly increased $L P L$ gene expression. The exercise session also significantly reduced expression of $S R E B F 1$ relative to rest $(n=7$ for skeletal muscle gene expression). (b) Resistance exercise significantly increased adipose tissue expression of FOXO1, PDK4, LPL, HSL and ADIPOQ, but

\section{Discussion}

We found that a single $1 \mathrm{~h}$ bout of resistance exercise $4.5 \mathrm{~h}$ prior to consumption of a mixed meal reduced total plasma TG, chylomicron-TG iAUC and TRL-TG iAUC but did not reduce VLDL-TG iAUC in men with prediabetes. In addition, we demonstrated that resistance exercise before a meal reduces the incorporation of both meal-derived and endogenous plasma fatty acids into TRL-TG and chylomicron-TG. Resistance exercise also increased whole-body postprandial lipid oxidation, which was further supported by increases in skeletal muscle lipid oxidation gene expression, lipoprotein lipase gene expression and skeletal muscle mitochondrial lipid respiration. Moreover, we demonstrated the novel finding that a single bout of resistance exercise significantly increased the expression of genes that enhance lipid metabolism in subcutaneous adipose tissue. Taken together, these data establish that resistance exercise acutely reduces postprandial lipaemia in men with prediabetes and provides insight into some of the underlying mechanisms. Additional studies of chronic resistance exercise training are needed to extend these findings.

In this study, a prior bout of resistance exercise reduced $\left[{ }^{13} \mathrm{C}_{4}\right]$ palmitate (exogenous) and $\left[\mathrm{U}_{-}{ }^{13} \mathrm{C}_{16}\right]$ palmitate (plasma) tracer concentration in chylomicron-TG. The mechanisms of the reduction in meal-derived palmitate are unclear, but we did identify a $\sim 17 \%$ increase in chylomicron-TG FCR after resistance exercise, as well as significant increases in whole-body and mitochondrial lipid oxidation, suggesting that improved clearance might be a contributing mechanism. The reduction in mean-derived palmitate might also be associated with a decline in splanchnic blood flow following exercise, which could reduce gastrointestinal motility and gastric emptying, thereby delaying the absorption of palmitate from the meal [27]. Alternatively, increased intestinal fatty acid oxidation, which was shown to occur after aerobic exercise, could reduce the substrate available for triacylglycerol synthesis and chylomicron secretion [28-30].

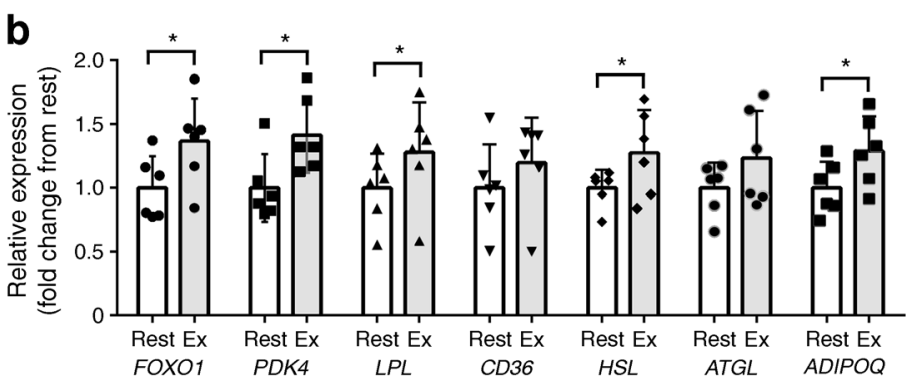

did not significantly change $C D 36$ or $A T G L$ expression ( $n=6$ for all genes). Values are mean fold change above rest (mean \pm SD) unless otherwise indicated. * Significant difference between rest and resistance exercise at $p<0.05$ for paired $t$ tests (parametric) or Wilcoxon signedrank tests (non-parametric). See results for corresponding $p$ values. ${ }^{\dagger}$ Denotes use of median \pm interquartile range for non-normally distributed data

The mechanism of the reduced incorporation of plasma fatty acids (endogenous) in chylomicrons is also unclear. We confirmed previous speculation that plasma NEFA can be taken up by the enterocyte from the portal system and packaged into chylomicrons, with plasma free palmitate making a $\sim 40 \%$ contribution to chylomicron- $\mathrm{TG}$ (the ${ }^{13} \mathrm{C}_{16}$ palmitate TTR plateau in chylomicrons is $\sim 40 \%$ of the plasma free palmitate TTR) [31]. However, the postprandial palmitate $R_{\mathrm{a}}$ was not affected by resistance exercise, nor was postprandial plasma NEFA concentration, so reduced systemic NEFA availability for enterocyte uptake and TG production was probably not a significant contributing factor to the reduced plasma palmitate in chylomicrons. These results suggest that changes in chylomicron formation or enterocyte lipid handling may contribute to reduced postprandial lipaemia following resistance exercise.

Further insight into intestinal lipid handling after resistance exercise is provided by the TTR of exogenous meal-derived $\left({ }^{13} \mathrm{C}_{4}\right)$ and plasma $\left({ }^{13} \mathrm{C}_{16}\right)$ palmitate in chylomicron-TG. The enrichments of the initial sources of these fatty acids were not different between rest and exercise (test meal $\left[\left({ }^{13} \mathrm{C}_{4}\right)_{3}\right]$ tripalmitin preparation; plasma $\left[\mathrm{U}_{-}{ }^{13} \mathrm{C}_{16}\right]$ palmitate infusion). Therefore, the lower TTR after resistance exercise compared with rest indicates increased isotopic dilution of both meal-derived and plasma palmitate by unlabelled palmitate in chylomicron-TG. The sources of unlabelled palmitate in chylomicrons are not clear, but there is mounting evidence that pre-existing lipids in the gastrointestinal tract appear in chylomicrons when new dietary fat and nutrients are absorbed [32,33]. Thus, resistance exercise appears to alter the relative contributions of meal-derived and plasma fatty acids compared with preexisting unlabelled fatty acids to chylomicron-TG production, resulting in greater isotopic dilution of the test meal ${ }^{13} \mathrm{C}_{4^{-}}$and plasma $\left[\mathrm{U}_{-}{ }^{13} \mathrm{C}_{16}\right.$ ]palmitate tracers. This mechanism could also contribute to the reduced meal-derived and plasma palmitate tracer concentration in chylomicron-TG if a greater portion of NEFA entering the enterocytes was 
diverted to replenish the cytosolic lipid droplet pool [34-36].

With regard to VLDL-TG, previous evidence suggests that a single bout $(1 \mathrm{~h})$ of resistance exercise and aerobic exercise (performed $30 \mathrm{~min}$ before a mixed meal) reduces postprandial VLDL-TG in obese women [14]. Similarly, in our study, we found a reduction in the incremental increase in plasma VLDL-TG after a meal (Table 2). Although it did not reach statistical significance, we identified a $\sim 30 \%$ increase in TRLTG FCR, suggesting that increased clearance could contribute to reduced VLDL-TG iAUC (since VLDL-TG accounted for $\sim 80 \%$ of TRL-TG).

We also found that a single session of resistance exercise increased adipose tissue expression of FOXO1, HSL and LPL. In adipose tissue, forkhead box protein $\mathrm{O} 1$ (FOXO1) activates a gene network involved in lipid mobilisation, glucose sparing, and inhibition of lipid storage/fat accumulation [37, 38]. Recent studies also showed that upregulation of FOXO1 in adipocytes during nutrient restriction enhances lysosomal degradation of lipid droplets (lipophagy), which generates NEFA that are used for cellular beta oxidation [39]. Increased lipophagy and fatty acid oxidation in adipose tissue could contribute to the finding that postprandial palmitate rates of appearance were not significantly higher than basal rates.

An additional mechanism for the blunted appearance of NEFA after resistance exercise would include increased NEFA recycling back into adipose TG [40]. We found that a single session of resistance exercise also increased the expression of PDK4 in adipose tissue; here, the protein product, pyruvate dehydrogenase kinase 4 , stimulates glyceroneogenesis to promote re-esterification of NEFA, limit excessive plasma NEFA release and divert glucose away from oxidation [41, 42]. The activation of genes involved in both adipose tissue lipolysis (FOXO1, HSL) and NEFA re-esterification (PDK4) could reflect increased activity of the adipose tissue TGNEFA cycle, which involves immediate re-esterification of the majority of NEFA liberated through adipose tissue lipolysis $[43,44]$.

We observed increases in whole-body lipid oxidation rate, skeletal muscle mitochondrial lipid respiration, as well as coupled and uncoupled respiration, complex Iand complex II-supported respiration, free oxidative phosphorylation capacity and the respiratory acceptor control ratio (an index of sensitivity to ADP). We also found a significant increase in the ratio of lipid to carbohydrate oxidation in skeletal muscle mitochondria, suggesting a greater contribution from NEFA for oxidation after resistance exercise. Similarly, skeletal muscle $L P L$ mRNA content increased following resistance exercise (though not significantly), suggesting increased TG hydrolysis and NEFA uptake may have accompanied higher lipid oxidation.
To our knowledge, this is the first study to demonstrate that acute resistance exercise increases the contribution of lipid oxidation to overall energy production. This increase occurs concurrently with enhanced skeletal muscle expression of PPARGC1A (the protein product of which, peroxisome proliferator-activated receptor- $\gamma$ coactivator- $1 \alpha$, upregulates genes coding for many proteins of tricarboxylic acid cycle, $\beta$-oxidation and fatty acid transport) [45]. In skeletal muscle, resistance exercise also upregulated the genes encoding PDK4 (which stimulates NEFA oxidation and shunts glucose toward glycogen storage) and FOXO1 (which stimulates PDK4 and PGC1 $\alpha$ expression), while reducing expression of SREBP1 (encoding sterol regulatory element binding transcription factor 1 , which inhibits fatty acid synthase) [46-48].

Finally, resistance exercise increased the expression of the adiponectin gene in adipose tissue (an adipokine associated with larger lipid droplet formation, increased insulin sensitivity and enhanced adipocyte NEA oxidation), which is typically downregulated in insulin-resistant conditions $[49,50]$. Higher adiponectin expression might have contributed to the reduced insulin concentration as well as the increase in wholebody lipid oxidation following resistance exercise.

\section{Limitations}

There are limitations to this study. First, we limited our analysis to overweight/obese, sedentary, middle-aged men with prediabetes. Further research is needed to investigate changes in lipid metabolism in response to resistance exercise in women, or in populations of different ages and activity levels. Additionally, we did not isolate VLDL for tracer enrichment analysis. Therefore, we used differences between TRL-TG and chylomicron metabolism to draw conclusions about VLDL metabolism. Our study was a priori powered to detect treatment effects of $\sim 1 \mathrm{SD}$ for paired differences between exercise and rest on postprandial plasma TG, lipoprotein clearance, NEFA $R_{\mathrm{a}}$ and $R_{\mathrm{d}}$, lipid oxidation and mitochondrial respiration, and gene expression. However our results indicated were underpowered to detect differences in TRL-TG and chylomicron FCR and basal NEFA $R_{\mathrm{a}}$ and $R_{\mathrm{d}}$ (effect sizes ranging $0.32-0.57$ for these outcomes).

\section{Conclusion}

We found that a single bout of resistance exercise reduces the lipaemic response to a mixed meal, and this reduction was mediated by diminished meal-derived and plasma fatty acid contributions to circulating lipoproteins, increased wholebody lipid oxidation, increased skeletal muscle mitochondrial lipid oxidation, and increased adipose tissue and skeletal muscle lipid oxidation gene expression. These changes might reduce the risk of CVD or progression to type 2 diabetes in men with prediabetes. 
Acknowledgements The authors would like to thank M. Giuffrida and K. Gratza for collection of muscle and adipose tissue biopsies, L. Ruvinov for preparing all stable isotope tracers for infusion for this study, S. Waller for preparing the standardised meals and the liquid test meals, T. Pietka for assistance with mitochondrial respiration analysis and $\mathrm{F}$. Custodio and J. Shew for help with sample preparation for GC-MS analysis (all from the Center for Human Nutrition, Washington University School of Medicine, St Louis, MO, USA). We also thank the nursing staff at the Washington University Institute for Clinical and Translational Sciences Clinical Research Unit (Washington University School of Medicine, St Louis, MO, USA) for their assistance with all study procedures.

Parts of this study were presented in poster form (poster 733-B) at the American Diabetes Association 78th Scientific Sessions in 2018.

Data availability The datasets generated/analysed during this study are available from the corresponding author on reasonable request.

Funding This work was supported by the National Institutes of Health T32 HD007434-25 (principal investigator C. E. Lang), UL1TR000448 (principal investigator B. Evanoff), and P30 DK056341 (Washington University Nutrition Obesity Research Center); the Foundation for Physical Therapy Promotion of Doctoral Studies II Scholarship (AJB); and the Cambridge Isotopes Laboratories Research Grant Program (WTC).

Duality of interest The authors declare that there is no duality of interest associated with this manuscript.

Contribution statement $\mathrm{AJB}, \mathrm{DCB}, \mathrm{BM}, \mathrm{BWP}$ and $\mathrm{WTC}$ designed the study. AJB, DCB, DNR and WTC conducted the studies. AJB, DCB, BWP, ALO, LCP, NAA, JY and WTC were involved in sample processing and analysis. AJB performed the statistical analyses. AJB drafted the manuscript and AJB, DCB, BM, BWP, ALO, JY, LCP, NAA, DNR and WTC critically reviewed the manuscript for important intellectual content and approved the final version to be published. AJB is the guarantor of this work and, as such, had full access to all the data in the study and takes responsibility for the integrity of the data and the accuracy of the data analysis.

\section{References}

1. Hamilton MT, Hamilton DG, Zderic TW (2007) Role of low energy expenditure and sitting in obesity, metabolic syndrome, type 2 diabetes, and cardiovascular disease. Diabetes 56(11):2655-2667. https://doi.org/10.2337/db07-0882

2. Sardinha LB, Magalhães JP, Santos DA, Júdice PB (2017) Sedentary patterns, physical activity, and cardiorespiratory fitness in association to glycemic control in type 2 diabetes patients. Front Physiol 8:262. https://doi.org/10.3389/fphys.2017.00262

3. Lahjibi E, Heude B, Dekker JM et al (2013) Impact of objectively measured sedentary behaviour on changes in insulin resistance and secretion over 3 years in the RISC study: interaction with weight gain. Diabetes Metab 39(3):217-225. https://doi.org/10.1016/j. diabet.2012.12.006

4. Bansal S, Buring JE, Rifai N, Mora S, Sacks FM, Ridker PM (2007) Fasting compared with nonfasting triglycerides and risk of cardiovascular events in women. JAMA 298(3):309-316. https:// doi.org/10.1001/jama.298.3.309

5. Karpe F, Steiner G, Uffelman K, Olivecrona T, Hamsten A (1994) Postprandial lipoproteins and progression of coronary atherosclerosis. Atherosclerosis 106(1):83-97
6. Colberg SR, Sigal RJ, Yardley JE et al (2016) Physical activity/ exercise and diabetes: a position statement of the american diabetes association. Diabetes Care 39(11):2065-2079. https://doi.org/10. 2337/dc16-1728

7. Petitt DS, Arngrímsson SA, Cureton KJ (2002) Effect of resistance exercise on postprandial lipemia. J Appl Physiol 94(2):694-700. https://doi.org/10.1152/japplphysiol.00377.2002

8. Heden TD, Winn NC, Mari A et al (2015) Postdinner resistance exercise improves postprandial risk factors more effectively than predinner resistance exercise in patients with type 2 diabetes. $\mathrm{J}$ Appl Physiol 118(5):624-634. https://doi.org/10.1152/ japplphysiol.00917.2014

9. Cohn JS, McNamara JR, Cohn SD, Ordovas JM, Schaefer EJ (1988) Postprandial plasma lipoprotein changes in human subjects of different ages. J Lipid Res 29(4):469-479

10. Shannon KA, Shannon RM, Clore JN, Gennings C, Warren BJ, Potteiger JA (2005) Resistance exercise and postprandial lipemia: the dose effect of differing volumes of acute resistance exercise bouts. Metabolism 54(6):756-763. https://doi.org/10.1016/j. metabol.2005.01.017

11. Henderson GC (2014) Sexual dimorphism in the effects of exercise on metabolism of lipids to support resting metabolism. Front Endocrinol (Lausanne) 5:162. https://doi.org/10.3389/fendo.2014. 00162

12. Gill JM, Frayn KN, Wootton SA, Miller GJ, Hardman AE (2000) Prior exercise and postprandial substrate extraction across the human leg. Am J Physiol Endocrinol Metab 279(5):E1020-E1028

13. Gill JM, Frayn KN, Wootton SA, Miller GJ, Hardman AE (2001) Effects of prior moderate exercise on exogenous and endogenous lipid metabolism and plasma factor VII activity. Clin Sci (Lond) 100(5):517-527

14. Davitt PM, Arent SM, Tuazon MA, Golem DL, Henderson GC (2013) Postprandial triglyceride and free fatty acid metabolism in obese women after either endurance or resistance exercise. J Appl Physiol 114(12):1743-1754. https://doi.org/10.1152/japplphysiol. 00095.2013

15. Gill JM, Al-Mamari A, Ferrell WR et al (2006) Effects of a moderate exercise session on postprandial lipoproteins, apolipoproteins and lipoprotein remnants in middle-aged men. Atherosclerosis 185(1):87-96. https://doi.org/10.1016/j.atherosclerosis.2005.06. 009

16. Adiels M, Mardinoglu A, Taskinen MR, Borén J (2015) Kinetic studies to elucidate impaired metabolism of triglyceride-rich lipoproteins in humans. Front Physiol 6:342. https://doi.org/10.3389/ fphys.2015.00342

17. Magkos F, Tsekouras YE, Prentzas KI et al (2008) Acute exerciseinduced changes in VLDL-triglyceride kinetics leading to hypotriglyceridemia manifest more readily after resistance than endurance exercise. J Appl Physiol 105(4):1228-1236. https://doi. org/10.1152/japplphysiol.90761.2008

18. Dias CB, Moughan PJ, Wood LG, Singh H, Garg ML (2017) Postprandial lipemia: factoring in lipemic response for ranking foods for their healthiness. Lipids Health Dis 16(1):178-111. https://doi.org/10.1186/s12944-017-0568-5

19. Huang Y, Cai X, Mai W, Li M, Hu Y (2016) Association between prediabetes and risk of cardiovascular disease and all cause mortality: systematic review and meta-analysis. BMJ 355:i5953. https:// doi.org/10.1136/bmj.i5953

20. Cade WT, Spencer CT, Reeds DN et al (2013) Substrate metabolism during basal and hyperinsulinemic conditions in adolescents and young-adults with Barth syndrome. J Inherit Metab Dis 36(1): 91-101. https://doi.org/10.1007/s10545-012-9486-x

21. Smith GI, Villareal DT, Lambert CP, Reeds DN, Mohammed BS, Mittendorfer B (2009) Timing of the initial muscle biopsy does not affect the measured muscle protein fractional synthesis rate during 
basal, postabsorptive conditions. J Appl Physiol (1985) 108(2): 363-368. https://doi.org/10.1152/japplphysiol.00957.2009

22. Fabbrini E, Yoshino J, Yoshino M et al (2015) Metabolically normal obese people are protected from adverse effects following weight gain. J Clin Invest 125(2):787-795. https://doi.org/10.1172/ JCI78425

23. Fabbrini E, Magkos F, Conte C et al (2012) Validation of a novel index to assess insulin resistance of adipose tissue lipolytic activity in obese subjects. J Lipid Res 53(2):321-324. https://doi.org/10. 1194/jlr.D020321

24. Carstensen M, Thomsen C, Hermansen K (2003) Incremental area under response curve more accurately describes the triglyceride response to an oral fat load in both healthy and type 2 diabetic subjects. Metabolism 52(8):1034-1037. https://doi.org/10.1016/ s0026-0495(03)00155-0

25. Patterson BW, Mittendorfer B, Elias N, Satyanarayana R, Klein S (2002) Use of stable isotopically labeled tracers to measure very low density lipoprotein-triglyceride turnover. J Lipid Res 43(2): 223-233

26. Zotou E, Magkos F, Koutsari C et al (2010) Acute resistance exercise attenuates fasting and postprandial triglyceridemia in women by reducing triglyceride concentrations in triglyceride-rich lipoproteins. Eur J Appl Physiol 110:869-874

27. Rehrer NJ, Smets A, Reynaert H, Goes E, De Meirleir K (2001) Effect of exercise on portal vein blood flow in man. Med Sci Sports Exerc 33(9):1533-1537. https://doi.org/10.1097/00005768200109000-00017

28. Hung Y, Linden MA, Gordon A, Scott Rector R, Buhman KK (2015) Endurance exercise training programs intestinal lipid metabolism in a rat model of obesity and type 2 diabetes. Phys Rep 3(1): e12232. https://doi.org/10.14814/phy2.12232

29. Kimura R, Takahashi N, Murota K (2011) Activation of peroxisome proliferator-activated receptor- $\alpha(\operatorname{PPAR} \alpha)$ suppresses postprandial lipidemia through fatty acid oxidation in enterocytes. Biochem Biophys Res Commun 410(1):1-6. https://doi.org/10. 1016/j.bbrc.2011.05.057

30. Pavlic M, Xiao C, Szeto L, Patterson BW, Lewis GF (2010) Insulin acutely inhibits intestinal lipoprotein secretion in humans in part by suppressing plasma free fatty acids. Diabetes 59(3):580-587. https://doi.org/10.2337/db09-1297

31. Chavez-Jauregui RN, Mattes RD, Parks EJ (2010) Dynamics of fat absorption and effect of sham feeding on postprandial lipema. Gastroenterology 139(5):1538-1548. https://doi.org/10.1053/j. gastro.2010.05.002

32. Robertson MD, Henderson RA, Vist GE, Rumsey RD (2002) Extended effects of evening meal carbohydrate-to-fat ratio on fasting and postprandial substrate metabolism. Am J Clin Nutr 75(3):505-510. https://doi.org/10.1093/ajcn/75.3.505

33. Xiao C, Stahel P, Carreiro AL, Buhman KK, Lewis GF (2018) Recent advances in triacylglycerol mobilization by the gut. Trends Endocrinol Metab 29(3):151-163. https://doi.org/10.1016/ j.tem.2017.12.001

34. Zhu B, Lee KK, Buhman JXC (2009) A dynamic, cytoplasmic triacylglycerol pool in enterocytes revealed by ex vivo and in vivo coherent anti-Stokes Raman scattering imaging. J Lipid Res 50(6):1080-1089. https://doi.org/10.1194/jlr.M800555JLR200

35. Vaugelade P, Posho L, Darcy-Vrillon B, Bernard F, Morel MT, Duée PH (1994) Intestinal oxygen uptake and glucose metabolism during nutrient absorption in the pig. Proc Soc Exp Biol Med 207(3):309-316. https://doi.org/10.3181/00379727-207-43821
36. Soayfane Z, Tercé F, Cantiello M et al (2016) Exposure to dietary lipid leads to rapid production of cytosolic lipid droplets near the brush border membrane. Nutr Metab (Lond) 13:48

37. Nakae J, Cao Y, Oki M, Orba Y, Sawa H (2008) Forkhead transcription factor FoxO1 in adipose tissue regulates energy storage and expenditure. Diabetes 57(3):563-576. https://doi.org/10.2337/ db07-0698

38. Chakrabarti P, Kandror KV (2009) FoxO1 controls insulindependent adipose triglyceride lipase (ATGL) expression and lipolysis in adipocytes. JBC 284(20):13296-13300. https://doi.org/10. 1074/jbc.C800241200

39. Lettieri Barbato D, Tatulli G, Aquilano K, Ciriolo MR (2013) FoxO1 controls lysosomal acid lipase in adipocytes: implication of lipophagy during nutrient restriction and metformin treatment. Cell Death Dis 4:e861

40. Granneman JG, Burnazi M, Zhu Z, Schwamb LA (2003) White adipose tissue contributes to UCP1-independent thermogenesis. Am J Physiol Endocrinol Metab 285(6):E1230-E1236. https:// doi.org/10.1152/ajpendo.00197.2003

41. Wan Z, Frier BC, Williams DB, Wright DC (2012) Epinephrine induces PDK4 mRNA expression in adipose tissue from obese, insulin resistant rats. Obesity (Silver Spring) 20(2):453-456. https://doi.org/10.1038/oby.2011.252

42. Cadoudal T, Distel E, Durant S et al (2008) Pyruvate dehydrogenase kinase 4: regulation by thiazolidinediones and implication in glyceroneogenesis in adipose tissue. Diabetes 57(9):2272-2279. https://doi.org/10.2337/db08-0477

43. Reshef L, Olswang Y, Cassuto H et al (2003) Glyceroneogenesis and the triglyceride/fatty acid cycle. J Biol Chem 278(33):3041330416. https://doi.org/10.1074/jbc.R300017200

44. Vallerand AL, Zamecnik J, Jones PJ, Jacobs I (1999) Cold stress increases lipolysis, FFA Ra and TG/FFA cycling in humans. Aviat Space Environ Med 70(1):42-50

45. Wu Z, Puigserver P, Andersson U (1999) Mechanisms controlling mitochondrial biogenesis and respiration through the thermogenic coactivator PGC-1. Cell 98(1):115-124. https://doi.org/10.1016/ S0092-8674(00)80611-X

46. Constantin-Teodosiu D (2013) Regulation of muscle pyruvate dehydrogenase complex in insulin resistance: effects of exercise and dichloroacetate. Diabetes Metab J 37(5):301-314. https://doi. org/10.4093/dmj.2013.37.5.301

47. Furuyama T, Kitayama K, Yamashita H, Mori N (2003) Forkhead transcription factor FOXO1 (FKHR)-dependent induction of PDK4 gene expression in skeletal muscle during energy deprivation. Biochem J 375(Pt 2):365-371. https://doi.org/10.1042/ BJ20030022

48. Nadeau KJ, Ehlers LB, Aguirre LE (2006) Exercise training and calorie restriction increase SREBP-1 expression and intramuscular triglyceride in skeletal muscle. Am J Physiol Endocrinol Metab 291(1):E90-E98. https://doi.org/10.1152/ajpendo.00543.2005

49. Kim JY, van de Wall E, Laplante M et al (2007) Obesity-associated improvements in metabolic profile through expansion of adipose tissue. J Clin Invest 117(9):2621-2637. https://doi.org/10.1172/ JCI31021

50. Slutsky N, Vatarescu M, Haim Y et al (2016) Decreased adiponectin links elevated adipose tissue autophagy with adipocyte endocrine dysfunction in obesity. Int J Obes 40(6):912-920. https://doi.org/ 10.1038/ijo.2016.5

Publisher's note Springer Nature remains neutral with regard to jurisdictional claims in published maps and institutional affiliations. 